\title{
EXPRESSION OF NESTIN AND VIMENTIN IN GLIOMATOSIS CEREBRI
}

\author{
Arlete Hilbig', Lígia Maria Barbosa-Coutinho², Nadima Toscani3, \\ Marlise de Castro Ribeiro ${ }^{4}$, Bartira Silveira Campos da Cunha ${ }^{5}$
}

\begin{abstract}
Gliomatosis cerebri (GC) is a rare form of CNS neoplasia in which there is diffuse involvement of the nervous tissue with or without the presence of tumor mass. The origin of the tumor is unknown, nor whether it represents a disease with diffuse onset or infiltration from a neoplastic focus. Here we studied the histopathologic characteristics of 6 cases with a diagnosis of GC and performed an immunohistochemical analysis using glial fibrillary acidic protein (GFAP), synaptophysin, nestin and vimentin. Most tumor cells were negative for GFAP, even though there were foci of positivity for this marker in all cases. We detected the presence of many positive cells for nestin and vimentin in all studied samples. The presence of these cells may indicate origin of the tumor from undifferentiated cells with a high degree of mobility.
\end{abstract}

KEY WORDS: gliomatosis cerebri, nestin, stem cell, brain tumor, neuropathology.

\begin{abstract}
Expressão de nestina e vimentina na gliomatosis cerebri
RESUMO - A gliomatosis cerebri (GC) é uma forma rara de neoplasia do sistema nervoso central em que existe o envolvimento difuso do tecido nervoso com ou sem a presença de massa tumoral. A origem do tumor é incerta, bem como se representa uma doença de início difuso ou uma infiltração a partir de um foco de neoplasia. Foram estudadas as características histopatológicas de seis casos com diagnóstico de GC e realizada imuno-histoquímica utilizando-se GFAP, sinaptofisina, nestina e vimentina. A maioria das células tumorais mostrou-se negativa para GFAP, apesar de existirem focos de positividade para este marcador em todos os casos. Observamos muitas células positivas para nestina e para vimentina em todas as amostras estudadas. Estas células poderiam indicar a origem do tumor em células multipotenciais com alto grau de mobilidade.
\end{abstract}

PALAVRAS-CHAVE: gliomatosis cerebri, nestina, célula-tronco, tumor cerebral, neuropatologia.

Gliomatosis cerebri (GC) is a rare neuroepithelial neoplasia which determines extensive diffuse infiltration into the brain tissue, causing expansion of the affected areas and sometimes determining formation of one or several tumor masses. Despite the diffuse infiltration, the architecture of the underlying brain tissue is relatively preserved. Clinical diagnosis is difficult because of the range of possible manifestations, including epilepsy, behavioral alterations, encephalopathy, pyramidal and exprapyramidal signs, and intracranial hypertension ${ }^{1-5}$. Radiological signs are nonspecific either and a correlation of clinical findings and imaging evidence is necessary with histopathological confirmation ${ }^{6}$. The term gliomatosis cerebri was introduced in 1938 by Nevin 7 , and it was considered a pathological entity by the $\mathrm{WHO}$ in 1979 , initially ascribed to the category of embryonic or undifferentiated tumor ${ }^{8,9}$. The neoplastic cells may show variable differentiation and resemble spongioblasts, astrocytes and oligodendrocytes, and present foci of glioblastoma multiforme. The histogenesis of GC is greatly debated, and because its origin remains unknown, it was withdrawn from the category of embryonic tumor and is currently classified as neuroepithelial neoplasia of unknown etiology with grade III or IV of malignancy. The mean survival time from the date of diagnosis is 14 months $^{2}$. It is still under discussion whether it represents diffuse neoplastic transformation or infiltration from one or more neoplastic foci $\mathrm{i}^{2,10,11}$.

\footnotetext{
Postgraduate Program in Pathology and Department of Morphological Sciences, Fundação Faculdade Federal de Ciências Médicas de Porto Alegre RS, Brazil (FFFCMPA): ${ }^{1}$ Neurologist, PhD in Medical Clinics UFRGS, Adjunct Professor Department of Morphological Sciences, FFFCMPA; ${ }^{2}$ Neuropathologist, Reader in Pathologic Anatomy FFFCMPA, Full Professor of Pathologic Anatomy FFFCMPA; ${ }^{3}$ Medical undergraduate student, FFFCMPA, scholarship student PIBIC-FAPERGS; ${ }^{4}$ Neurologist, PhD in Medical Clinics, UFRGS; ${ }^{5}$ Master student at the Postgraduate Program in Pathology FFFCMPA.
}

Received 9 March 2006, received in final form 12 June 2006. Accepted 29 June 2006.

Dra. Arlete Hilbig - Rua Sarmento Leite 245 - 90050-170 Porto Alegre RS - Brasil. E-mail: hilbiga@fffcmpa.edu.br 
The present model of tumor classification is based on the developmental stage of the cell originating the tumor. Advances in the understanding of the biology of central nervous system (CNS) stem cells (SC) have suggested that those cells may have oncogenic properties ${ }^{12-14}$. There are some similarities between normal and tumor stem cells, such as ability to selfrenovate and to generate multipotent cells, and there may be transdifferentiation between different cell types ${ }^{14}$. Stem cells have been identified in different areas of the adult CNS and in CNS neoplasia through their immunohistochemical characteristics.

The aim of the present study is to analyze the cell components, as well as their degree of maturity in $\mathrm{GC}$, based on the expression of cytoskeletal proteins, using immunohistochemical techniques.

\section{METHOD}

Six cases with a diagnosis of gliomatosis cerebri were studied coming from the neuropathologic examinations performed by one of the authors (LMBC). The diagnosis was based on clinical suspicion and imaging techniques and confirmed through routine histopathological examination. After a review of the cases an immunohistochemical investigation was performed, as briefly described below, using the primary antibodies listed in Table. The clinical data and the neuroimaging examinations were provided by the neurosurgeon who referred the material.
Immunohistochemistry - All studied tissues were previously fixed in $10 \%$ formalin and embedded in paraffin. The blocks were cut into $5-\mu \mathrm{m}$ thick sections and mounted onto slides prepared with organosilane. The slides were then deparaffined and processed for immunohistochemistry through the following steps: (1) antigenic recovery, as necessary; (2) blockage of endogenous peroxidase in methanol and $\mathrm{H}_{2} \mathrm{O}_{2} ;$ (3) incubation in normal serum; (4) overnight in primary antibody in refrigerator; (5) specific secondary antibody (Novocastra lab); (6) streptoavidin-biotin-peroxidase complex (Novocastra lab); (7) 3-3' diaminobenzidin/ $\mathrm{H}_{2} \mathrm{O}_{2}$ and counterstaining with hematoxylin. Between each step the tissue was washed 3 times in phosphate buffer solution (PBS). Brain tissue of human fetus with 20 weeks of gestation was used as control for nestin. The positive control for GFAP and synaptophysin was normal brain tissue, and for vimentin the vessels of the studied tissue itself were used as control. The negative control was done by omitting the primary antibody overnight.

\section{RESULTS}

The age of the patients ranged from 11 to 53 years (mean: 32.5 years). Four patients were females and two were males. The imaging investigation showed that all patients presented involvement of at least two cerebral lobes (Fig 1). Tumor localization was largely temporal and parietal in three cases, frontal and parietal in two cases, and occipital and temporal in one. Three patients also presented tumor

Table. Antibodies used in the study.

\begin{tabular}{lllll}
\hline Antibody (type) & Source & Retrieval & Dilution & Specificity \\
\hline Synaptophysin (monoclonal) & DAKO & $\begin{array}{l}\text { Heating in citrate buffer } \\
\mathrm{pH} 6.0(20 \mathrm{~min})\end{array}$ & $1: 100$ & Synaptic gap membrane protein - neurons \\
Vimentin (monoclonal) & DAKO & Not performed & $1: 800$ & $\begin{array}{l}\text { Intermediate filament protein in } \\
\text { mesenchymal tissue }\end{array}$ \\
$\begin{array}{l}\text { GFAP (monoclonal) } \\
\text { Nestin (polyclonal) }\end{array}$ & DAKO & Not performed & $1: 800$ & Glial fiber acid protein \\
& Chemicon & $\begin{array}{l}\text { Heating in citrate buffer } \\
\text { pH } 6.0(20 \mathrm{~min})\end{array}$ & $1: 100$ & $\begin{array}{l}\text { Intermediate filament protein in primitive } \\
\text { stem } / \text { neuroepithelial cells }\end{array}$ \\
\hline
\end{tabular}

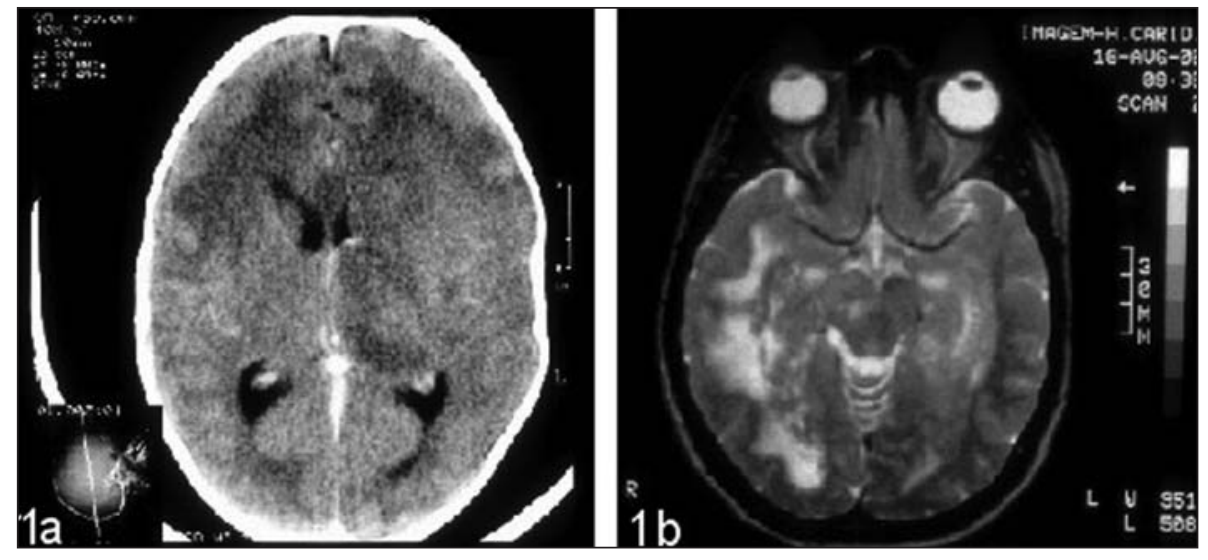

Fig 1. Neuroradiologic examination in GC. (A) CT scan showing diffuse infiltration and presence of tumor mass with contrast enhancement; (B) MRI examination T2-weighted showing diffuse lesion with mass effect. 


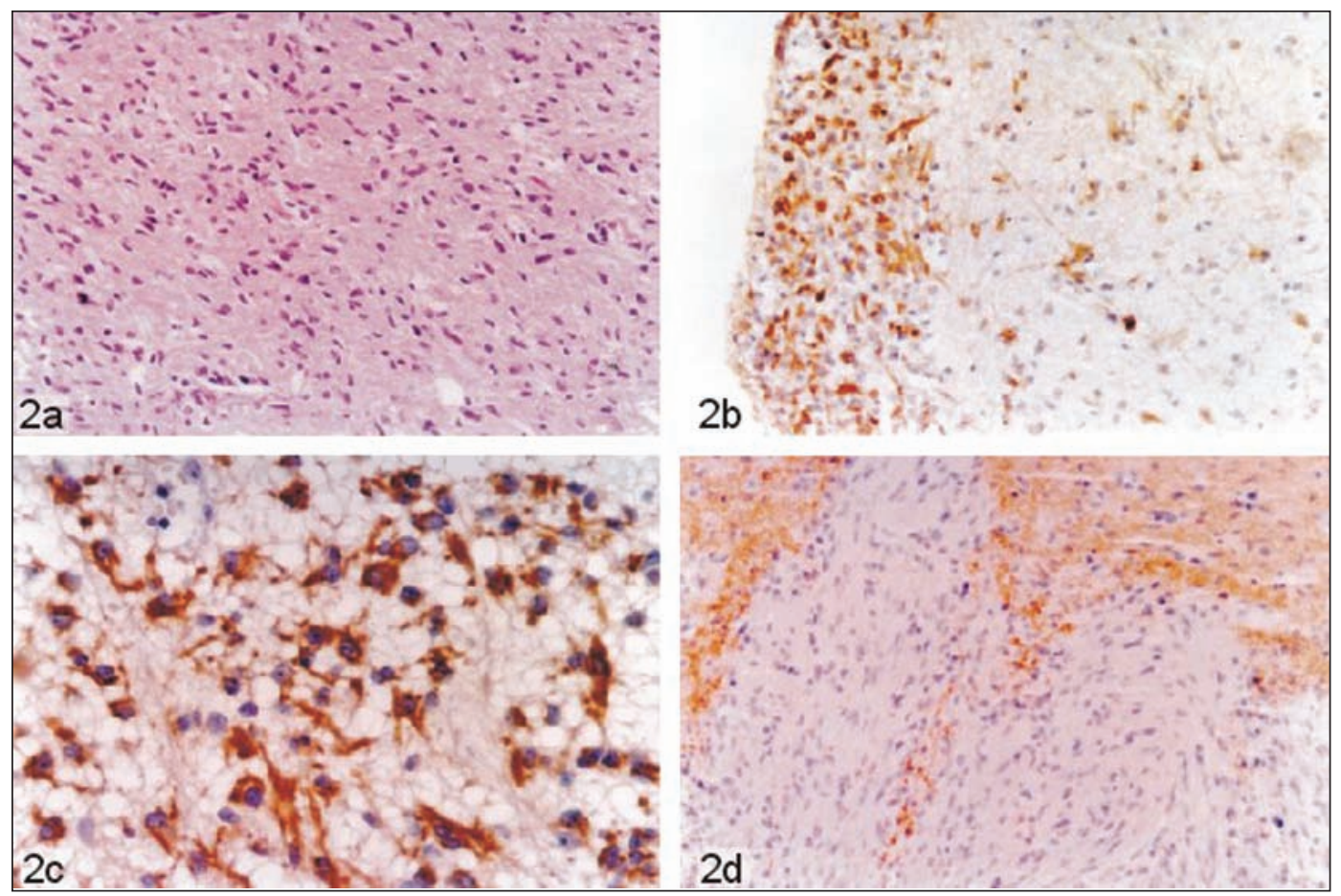

Fig 2. (A) H-E staining (obj. 20X); (B) Tumor cells in the subarachnoid space positive for GFAP (obj. 20X); (C) GFAP expression in an area with astrocytic appearance (obj. 40X); (D) ICC with synaptophysin showing tumor infiltration and expression in remaining tissue (obj. 20X).

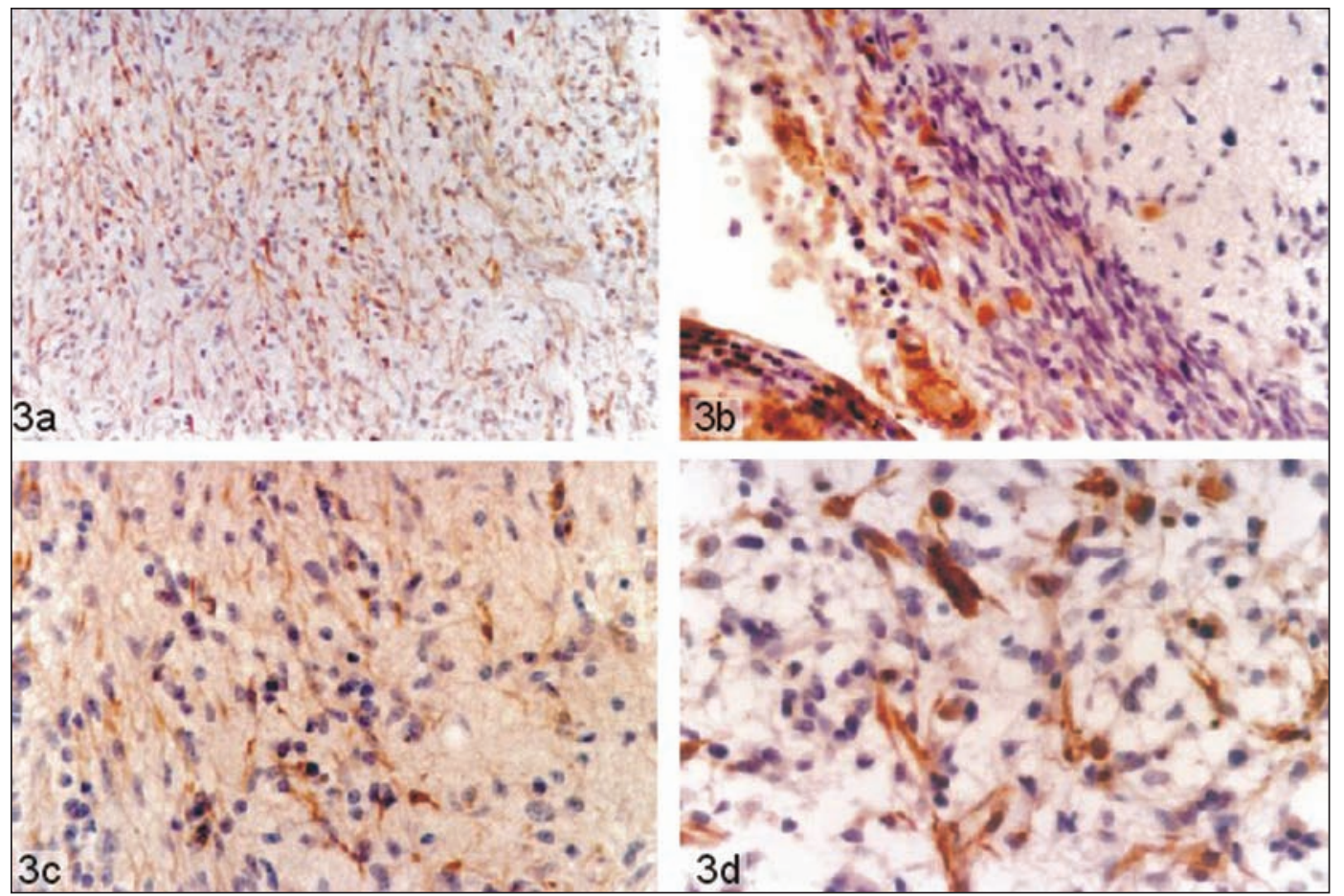

Fig 3. (A) Expression of vimentin in GC (obj. 20X); (B) Vimentin positivity in subaracnoid space infiltration; (C) and (D) Nestin expression in GC (obj. 40X). 
masses. In the other three patients there was diffuse increase of the affected areas, without apparent tumor mass. A patient biopsied in two different areas presented more malignancy in one of these areas, this specimen being diagnosed as glioblastoma.

The histopathological examination of the biopsied nervous tissue revealed diffuse infiltration by cells with oval or fusiform nucleus, with no apparent proliferation and few mitotic figures (Fig 2A). The tissue underlying the tumor was partially preserved. Besides diffuse infiltration by more undifferentiated cells, there were foci with a predominantly astrocytic characteristics in four cases and of glioblastoma in one case. In one case there were areas of oligodendroglial appearance. In three cases there was major infiltration of the molecular layer of the cortex and subarachnoid space, as well as perivascular infiltration (Fig 2B).

Immunohistochemistry for GFAP, a marker of glial cells, showed positive foci in all cases, particularly in areas presenting astrocytic characteristics (Fig 2C). Despite some areas of positivity, most tumor cells were negative for GFAP. In addition to tumor cells there was positivity in reactive astrocytes along the tumor. Synaptophysin was positive in the areas of the remaining brain tissue invaded by the tumor, but was negative in tumor cells (Fig 2D).

All cases presented positivity of varying intensity for vimentin and nestin (Fig 3), which are cytoskeletal proteins present mainly in immature cells. Positivity occurred in cells with a more undifferentiated appearance along the tumor infiltration and in areas of dissemination through the subarachnoid space, showing that many tumor cells were positive for these markers. In areas where there was clear positivity for GFAP few cells were positive.

\section{DISCUSSION}

Gliomatosis cerebri is a diffuse infiltrating disease which, although rare, must be considered as differential diagnosis in patients presenting progressive neurological deterioration and diffuse and expansive damage to the nervous tissue, with or without apparent tumor mass. The tumor uses the anatomic routes for dissemination, with little or no destruction of the involved structures. The findings in CT scans can be subtle and of difficult visualization, with iso- to hypodense lesions, variable mass effect and no contrast enhancement. MRI is an important tool for the diagnosis: T1-weighted images usually show iso- to hypointense, poorly defined lesions; on T2-weighted and proton-density images, the lesion may show increased signal intensity, with a diffuse mass effect. Affected areas may be large, even with mild clinical manifestations. Usually there is no contrast enhancement ${ }^{6}$ and there may be one or more tumor masses, in addition to diffuse infiltration. Sanson et al. ${ }^{15}$ suggest using the terms primary gliomatosis when there is no defined mass and secondary gliomatosis when there is a tumor mass which seems to progress towards involvement of more than one lobe. Several diseases can determine similar alterations in imaging scans: ischemic, demyelinating, inflammatory diseases or other tumors such as low grade gliomas. Therefore, the histopathological examination is crucial and must be correlated with clinical and imaging data.

Histopathology shows diffuse infiltration by tumoral cells with variable mitotic activity but without any significant endothelial alteration. In one of our cases, one area presented a more malignant aspect with a diagnosis of glioblastoma, something also reported by other authors ${ }^{1,2,6}$. Tumor cells show great variation in shape, size, mitotic activity and differentiation degree. The adaptation of tumor cells to the local architecture of the fibers is typical, mostly being composed of long, bipolar cells. Usually there is a concentration of small cells on the molecular layer of the brain cortex and dissemination into the subarachnoid space, which occurred in half the cases studied here. The process is diffuse and may involve cerebrum, cerebellum, brainstem and even the spinal cord. Although the phenotype in some areas suggests origin in glial cells, the expression of GFAP, a protein of the intermediate filament typical of astrocytes, is variable and absent in most cells. Along the tumor we can find reactive astrocytes that are positive for GFAP, with negative tumor cells.

Intermediate filaments comprise a large family of cytoskeletal proteins whose sequential expression has been used to define the progress of cell development in the CNS. These proteins are regulated by development, there being modifications with the stage of cell differentiation. They present tissue specificity, differently from microtubules and microfilaments. Nestin is an intermediate protein class $\mathrm{VI}$ with early expression in the CNS - 6 to 40 weeks of gestation - and is correlated with the period of proliferation of progenitor cells ${ }^{16}$. Besides progenitor cells, it seems to be expressed as well in cells in transition from the progenitor stage to a more differentiated form, where it initiates the expression of other intermediate proteins, such as GFAP or neurofilament. Therefore, there is a period of co-expression that is temporarily distinct for glial and neuronal differen- 
tiation ${ }^{16}$. In the mature human CNS, differently from what was once thought, the expression of nestin occurs at least in three cell types. There is expression in neuron-like cells, co-expressed with neuron-specific enolase, especially in the hippocampus, amygdala, and Meynert basal nucleus; astrocyte-like cells in the subependymal zone and subgranular layer of dentate gyrus; and cells with smaller cell bodies and fewer processes also in the subependymal zone and subgranular layer of dentate gyrus ${ }^{17}$. The latter are probably related to progenitor cells which, in the adult CNS, appear to have a limited potential for development, giving rise to glial cells and GABAergic interneurons ${ }^{18}$. Nestin may also be expressed in endothelial cells. Therefore, though absent in the cortical region, several reservoirs are available along the CNS. Vimentin is not only present in all mesenchymal tissue but also appears transitionally in a variety of cells during development and may be co-expressed with nestin in the CNS ${ }^{16,19}$. The two major IF proteins of astrocytes are vimentin and GFAP. Early during development, radial glia and immature astrocytes express mainly vimentin. Towards the end of gestation, a switch occurs and vimentin is progressively replaced by GFAP in differentiated astroglial cells, although some mature astrocytes can still express vimentin. In our cases we found expression of vimentin in tumor cells of areas that were positive for nestin as well.

The absence of expression for GFAP or synaptophysin indicates that a cell is not yet committed to specific differentiation. However, co-expression of nestin and GFAP has already been described during the period of developmental transition and in reactive astrocytes after CNS lesion ${ }^{20-22}$. Positivity for nestin in damaged areas of the CNS suggests that there may be a re-expression in pathological situations and/or that these cells have a tropism to damaged areas and may differentiate into astrocytes in these regions.

The immunohistochemical findings reported here demonstrate the expression of nestin and vimentin in many cells in GC. The extension of tissue infiltration in this type of tumor supports the idea of a neoplasia of diffuse origin and/or from cells with extreme motility. It is possible that immature cells that are positive for nestin may be the origin of the tumor and there is enhanced glial differentiation in some areas, depending on local characteristics. On the other hand, it is also possible that these undifferentiated cells come from dedifferentiation of tumoral cells of astrocytic origin, which come to express proteins associated with great cell motility. Florenes et al. ${ }^{23}$ have demonstrated expression of nestin in infiltrat- ing tumor cells of metastatic melanoma, suggesting an association of its expression with tumor invasion. The co-expression of vimentin and nestin was also described previously in astrocytoma cell lines with enhanced motility and invasive potential ${ }^{24}$. Cells of invasive gliomas show a decreased proliferation rate and a relative resistance to apoptosis, similar to what has occurred in $\mathrm{GC}^{8,9}$.

Genetic studies conducted thus far do not allow to confirm or rule out any of these possibilities. Kros et al. $^{10}$, studying the genetic alterations in a single patient autopsied with GC, acknowledged the presence of the same specific group of alterations in different areas, suggesting a monoclonal proliferation of the tumor. Mawrin et al. ${ }^{11}$ studied 18 cases coming from biopsies $(n=10)$ and necropsies $(n=8)$ and showed that TP53 is altered in some cases, but they suggest that other yet unidentified genetic alterations may contribute to tumorigenesis in GC and that the presence of different clones in the tumor cannot be ruled out.

The presence of nestin does not seem to be related to cellular mitotic activity but rather with its differentiation, which may explain the absence of expressive mitotic activity and of endothelial hyperplasia in a tumor that causes diffuse involvement and has a poor prognosis, comparable to glioblastoma. Positivity for nestin has already been demonstrated in other CNS tumors: co-expression with GFAP or neurofilament in medulloblastoma and with GFAP in glial tumors of all grades ${ }^{8,9}$. The low grade tumors associated with epilepsy, such as ganglioglioma and DNT, also show variable positivity for nestin ${ }^{25}$. Studies are lacking to determine the role of these cells in carcinogenesis and the prognostic importance in different tumor types.

The possibility that stem cells play some role in the origin of CNS tumors is a very relevant issue and has serious implications regarding the potential treatment of patients with acquired brain lesions or neurodegenerative disorders. It is important to remember that these cells have characteristics that differ from more mature cells and that perhaps their presence should be considered in planning treatments for CNS neoplasms.

\section{REFERENCES}

1. Artigas J, Cervos-Navarro J, Iglesias JR, Ebhardt G. Gliomatosis cerebri: clinical and histological findings. Clin Neuropathol 1985;4:135-148.

2. Herrlinger U, Felsberg J, Kuker W, et al. Gliomatosis cerebri: molecular pathology and clinical course. Ann Neurol 2002;52:390-399.

3. Shahar E, Kramer U, Nass D, Savitzi D. Epilepsia partialis continua associated with widespread gliomatosis cerebri. Pediat Neurol 2002;27: 392-396. 
4. Izumiyama H, Abe T, Tanioka D. Gliomatosis cerebri in a young patient showing various cranial nerve manifestations: a case report. Brain Tumor Pathol 2003;20:93-96.

5. Filley C, Kleinschmidt-DeMasters BK, Lillehei KO, et al. Gliomatosis cerebri: neurobehavioral and neuropathological observations. Cogn Behav Neurol 2003;16:149-159.

6. Freund M, Hahnel S, Sommer C, et al. CT and MRI findings in gliomatosis cerebri: a neuroradiologic and neuropathologic review of diffuse infiltrating brain neoplasm. Eur Radiol 2001;11:309-316.

7. Nevin S. Gliomatosis cerebri. Brain 1938;61:170-191.

8. Zülch KJ. Histological typing of tumors of the central nervous system. Geneva: Word Health Organization, 1979.

9. Lantos PL, Louis DN, Rosenblum MK, Kleihues P. Tumors of he nervous system. In Graham and Lantos (eds.) Greenfield's Neuropathology Seventh Edition. London: Arnold, 2002:767-1052.

10. Kros JM, Zheng P, Dinjens WN, Alers JC. Genetic aberrations in gliomatosis cerebri support monoclonal tumorigenesis. J Neuropathol Exp Neurol 2002;61:806-814.

11. Mawrin C, Kirches E, Schneider-Stock R, et al. Analysis of TP53 and PTEN in gliomatosis cerebri. Acta Neuropathol (Berl) 2003;105:529-536.

12. Uchida K, Mukai M, Okano H, Kawase T. Possible oncogenicity of subventricular zone neural stem cells: case report. Neurosurgery 2004; 55:977-987.

13. Singh SK, Clarke ID, Hide T, Dirks PB. Cancer stem cells in nervous system tumors. Oncogene 2004;23:7267-7273.

14. Pilkington GJ. Cancer stem cells in mammalian central nervous system. Cell Proliferation 2005;38:423-433.

15. Sanson M, Cartalat-Carel S, Taillibert S, et al. Initial chemotherapy in gliomatosis cerebri. Neurology 2004;63:270-275.
16. Messam CA, Hou J, Berman JW, et al. Analysis of the temporal expression of nestin in human fetal brain derived neuronal and glial progenitor cells. Brain Res Dev 2002;134:87-92.

17. Gu H, Wang S, Messam CA, Yao Z. Distribution of nestin immunoreactivity in the normal adult human forebrain. Brain Res 2002;943: 174-180.

18. Scheffler B, Walton NM, Lin DD, et al. Phenotypic and functional characterization of adult brain neuropoiesis. PNAS 2005;102:9353-9358.

19. Gomes FCA, Paulin D, Moura Neto V. Glial fibrillary acidic protein (GFAP): modulation by growth factors and its implication in astrocyte differentiation. Br J Med Biol Res 1999;32:619-631.

20. Kaya SS, Mahmood A, Li Y, et al. Expression of nestin after traumatic brain injury in rat brain. Brain Res 1999;840:153-157.

21. Lin RCS, Matesic DF, Marvin M, et al. Re-expression of the intermediate filament nestin in reactive astrocytes. Neurobiol Disease 1995;2: 79-85.

22. Douen AG, Dong L, Vanance S, et al. Regulation of nestin expression after cortical ablation in adult rat brain. Brain Res 2004:1008:139-146.

23. Florenes VA, Holm R, Myklebost O, et al. Expression of the neuroectodermal intermediate filament nestin in human melanomas. Cancer Res 1994;54:354-359.

24. Rutka JT, Ivanchuk S, Mondal S, et al. Co-expression of nestin and vimentin intermediate filaments in invasive human astrocytoma cells. Int J Dev Neurosci 1999;17:503-515.

25. Hilbig A, Barbosa-Coutinho LM, Ribeiro M, et al. The presence of immature cells in cortical dysplasia, dysembrioplastic neuroepithelial tumours and gangliogliomas: are they related conditions? Epilepsia 2003;44:90. 